\title{
Benefits of Baculovirus Use in IPM Strategies for Open Field and Protected Vegetables
}

\author{
Anna Landwehr* \\ Andermatt Biocontrol Suisse AG, Grossdietwil, Switzerland
}

Widespread use of synthetic chemical insecticides causes growing concern regarding the risks to human health and negative impacts on the environment. At the same time, many insects have become resistant toward synthetic chemical insecticides. Baculoviruses bring many benefits and allow reduced use of synthetic insecticides when included in integrated pest management (IPM). They are specific to their target pest and thus do not have any negative effects on plants, mammals, and non-target insects including natural enemies and pollinators. In addition, their unique mode of action makes them suitable for resistance management. We provide examples of how baculoviruses can be applied in IPM strategies for open field and protected vegetable crops. In field trials, baculovirus products were applied in rotations and tankmixes with chlorantraniliprole, Bacillus thuringiensis products, and spinosad and provided promising control of target pests. The conducted trials in open field and protected vegetables show that baculoviruses can offer an effective solution to control pests in open field and protected vegetable production. Including baculoviruses gave results as good as other application strategies tested while conferring important benefits in reducing residues and improving the resistance management strategy.

Caroline Knox

Rhodes University, South Africa David Grzywacz,

University of Greenwich,

United Kingdom

*Correspondence:

Anna Landweh

anna.landwehr@biocontrol.ch

Specialty section:

This article was submitted to

Crop Biology and Sustainability,

a section of the journal

Frontiers in Sustainable Food Systems

Received: 13 August 2020 Accepted: 28 December 2020

Published: 29 January 2021

Citation:

Landwehr A (2021) Benefits of Baculovirus Use in IPM Strategies for Open Field and Protected Vegetables. Front. Sustain. Food Syst. 4:593796. doi: 10.3389 /fsufs. 2020.593796

Keywords: baculovirus, integrated pest management (IPM), sustainable agriculture, spodoptera exigua NPV, autographa californica NPV, trichoplusia ni, helicoverpa zea NPV

\section{INTRODUCTION}

Widespread use of synthetic chemical insecticides causes growing concerns regarding the negative impacts on the environment. There are various documentations on the negative effects of synthetic chemical insecticides on beneficial insects in vegetable crops (Smagghe et al., 2013; Fernandes et al., 2016). Biological control agents for aphids, whitefly, thrips and mites control are commonly used especially in greenhouse production and use of insecticides is a concern for the pest management program, as they may have sublethal or lethal effects on such macrobials (Fernandes et al., 2016). Pyrethroids such as lambda-cyhalothrin have shown to reduce species of Cycloneda sanguinea, Orius insidiosus and Chauliognathus flavipes up to $100 \%$ in field trials in tomato crops (Fernandes et al., 2016). The same effect of this active ingredient on beneficials was found in a study by Ditillo et al. (2016) on tomato regarding populations of Phytoseiulus persimilis. Galvan et al. (2005) found lambda-cyhalothrin to significantly reduce populations of Harmonia axyridis on sweet corn. Other active ingredients, such as chlorantraniliprole have shown not to strongly affect the mentioned species, however bumblebee's activity for pollination has been demonstrated to be reduced when the insecticide was applied (Smagghe et al., 2013; Fernandes et al., 2016). 
At the same time many insects have become resistant toward synthetic chemical insecticides (Lasa et al., 2007; Lacey et al., 2008; Wang et al., 2018). Furthermore, the public awareness for residue free produce is growing and more and more chemical substances are banned for use in agricultural production. Because of this, more environmentally and consumer friendly solutions for crop protection are needed. Strategies to enable the possibility of integration of biological control with synthetic chemical insecticides need to be evaluated to reduce the number of insecticide applications and minimize the likelihood of pest resurgence (Galvan et al., 2005).

Baculoviruses have been used worldwide to control insects in agriculture. As they have been widely adopted in biological production, they are moving toward further use in integrated agricultural production systems (Lacey et al., 2015). Several reasons make them ideal products for residue free production (Moscardi et al., 2011; Lacey et al., 2015). Their unique mode of action allows baculoviruses to only infect their specific target pests (Szewczyk et al., 2009). They do not produce any toxins or metabolites which could be a concern regarding human health. Furthermore, baculoviruses are inactivated with time when exposed to UV-light and deposits of active ingredient cannot build up on harvested produce.

For above reasons, baculoviruses in plant protection products are exempted from restrictions regarding maximum residue levels on produce [e.g., Reg (EC) No 396/2005 (MRL)]. Therefore, also the OECD concludes in a consensus paper that baculoviruses are safe for user and consumer, as well as non-toxic to plants, aquatic organisms, and mammals (Environmental directorate, Organisation for Economic Cooperation and Development, 2002). In the USA baculoviruses in plant protection products are regulated by the Environmental Protection Agency (EPA). Although regulations are similar to those in the EU, baculovirus products intended for use on fooduse sites are not per-se but only exempted from maximum tolerance levels if a corresponding tolerance exemption has been established (Environmental Protection Agency, 2014).

Besides concerns on human health and negative environmental effects, the use of broad-spectrum insecticides has also resulted in outbreaks of secondary pests and insecticide resistance across several production systems (Lasa et al., 2007; Lacey et al., 2008). For example, Spodoptera exigua is a major pest of different vegetable crops in Spanish greenhouses and has been controlled by broad-spectrum insecticides (Lasa et al., 2007). Frequent use of chemical insecticides has resulted in widespread resistance of S. exigua populations in Spain (Lasa et al., 2007). In different Chinese districts, $S$. exigua populations have been found to be resistant toward chlorantraniliprole (Wang et al., 2018). In corn, management of Helicoverpa zea is becoming increasingly ineffective due to resistance toward pyrethroids and certain Bt corn varieties. A study conducted by Harrison and Hoover (2012) concludes that baculoviruses are a potential possibility for approaching the management of $H$. zea under these circumstances. At the same time, monitoring of pesticide residue on the produce has increased and therefore the need for effective plant protection solutions, which are compatible with residue requirements are urgently needed.
Despite these major benefits of baculoviruses, their specificity also leads to relatively low acceptance in production systems where pests occur in complexes. However, above mentioned concerns increase the need to implement baculoviruses also for cropping systems, in which multiple pests occur. Therefore, we have been testing different strategies of including baculoviruses into current practices with broad spectrum insecticides. In the described field trials, baculovirus products were applied in rotations and tankmixes with chlorantraniliprole, Bacillus thuringiensis products and spinosad.

\section{METHODS}

Four trials with different, commercially available baculovirus products were performed in open field and under protected production. Spexit, a Spodoptera exigua nucleopolyhedrovirus (SeMNPV, $3.75 \times 10^{12} \mathrm{OB} / \mathrm{L}$, SC formulation, manufactured by Andermatt Biocontrol Suisse AG in Switzerland,) was tested for control of Spodoptera exigua in tomato. Loopex based on Autographa californica nucleopolyhedrovirus (AcNPV, $5 \times 10^{11}$ $\mathrm{OB} / \mathrm{L}, \mathrm{SC}$ formulation, manufactured by Sylvar Technologies Inc. in Canada) was used in a trial for control of Trichoplusia ni in broccoli. Spexit and Loopex were also tested in a trial for control of S. exigua and T. ni in cabbage. Helicovex, based on Helicoverpa armigera nucleopolyhedrovirus (HearNPV, $7.5 \times 10^{12} \mathrm{OB} / \mathrm{L}$, SC formulation, manufactured by Andermatt Biocontrol Suisse AG in Switzerland) was tested for control of Helicoverpa zea in sweet corn. The aim of all trials was to improve efficacy of existing solutions and reducing residues on the crop by reducing application rates of chemicals. The baculoviruses were rotated or tankmixed with chlorantraniliprole, Bacillus thuringinesis products, spinosad, spinetoram, and methoxyfenozide.

\section{Spexit (SeNPV) on Tomato}

The efficacy of Spexit to control S. exigua infestations on fresh market tomato was assessed in Escalon, California (USA) in a trial by Two Bees Agricultural Research and Consulting on their agricultural research farm. The trial was conducted between September and November 2016 on fresh market tomato of the variety Quality 47, using a randomized complete block design (RCBD) with four replications. For the trial sufficient natural infestation of $S$. exigua was present. The timing of the first application was determined by pheromone traps and performed as soon as the first moths were captured by the traps. At that time plants were in $\mathrm{BBCH}$ stage 72 . The seven tested treatments included an untreated control, Spexit low application rate $(75 \mathrm{ml} / \mathrm{ha})$, Spexit high application rate $(180 \mathrm{ml} / \mathrm{ha})$, Bacillus thuringiensis subsp. aizawai (Bta), Spexit (75 ml/ha) + Bta (tankmix), Spexit $(180 \mathrm{ml} / \mathrm{ha})+$ spinosad (in rotation) as well as $\mathrm{Bta}+$ spinosad (in rotation). The $75 \mathrm{ml} / \mathrm{ha}$ rate of Spexit equals $2.81 \times 10^{11} \mathrm{OB} / \mathrm{ha}$, the $180 \mathrm{ml} /$ ha equals $6.75 \times 10^{11} \mathrm{OB} / \mathrm{ha}$. On each plot $(4 \times 6 \mathrm{~m}$, row spacing $1.5 \mathrm{~m})$, seven applications with 7 -day intervals were conducted for each treatment. Assessments were done as counts of larvae per 100 plants per plot, followed by fruit damage rating as fruit neared maturity during trial and at harvest. The percentage of damaged fruit was assessed from 100 fruits after the fifth and seventh application. Data 
were analyzed using analysis of variance, followed by the LSD post-hoc test.

\section{Loopex (AcNPV) on Broccoli}

The efficacy of Loopex to control T. ni infestations on broccoli was assessed in Escalon, CA (USA) in a trial by Two Bees Agricultural Research and Consulting on their agricultural research farm. The trial was conducted between July and October 2016 using a RCBD with four replications and the Broccoli variety Greenbelt. For the trial sufficient natural infestation of $T$. $n i$ was present. At the first application, plants were in $\mathrm{BBCH}$ stage 14. The tested treatments included an untreated control, Loopex low application rate $(=50 \mathrm{ml} / \mathrm{ha})$, Loopex high application rate (200 ml/ha), Bacillus thuringiensis subsp. kurstaki (Btk) as well as Loopex $(75 \mathrm{ml} / \mathrm{ha})+$ Btk tankmixed. The $50 \mathrm{ml} /$ ha rate of Loopex equals $2.50 \times 10^{10} \mathrm{OB} / \mathrm{ha}$, the $75 \mathrm{ml} /$ ha equals $3.75 \times 10^{10} \mathrm{OB} / \mathrm{ha}$ and $200 \mathrm{ml} / \mathrm{ha}$ of Loopex equals $1.00 \times 10^{11} \mathrm{OB} / \mathrm{ha}$. On each plot $(5 \times 12 \mathrm{~m}, 0.3 \mathrm{~m}$ row-spacing $)$ eight applications with 7day intervals were conducted for each treatment. The efficacy was evaluated by a larval count assessment before the first application and 7 days after each application. The number of larvae per 10 plants was counted and feeding damage was assessed as percent of foliar damage. Assessments were done on a weekly basis. Data analysis was performed by analysis of variance, followed by the LSD post-hoc test.

\section{Spexit (SeNPV) and Loopex (AcNPV) on Cabbage}

The efficacy of the combination of Spexit and Loopex to control areas with both pest species present on cabbage was assessed in Holtville, CA (USA) by the cooperative extension of the University of California on plots of the Desert Research \& extension center Holtville. The trial was conducted between September and November 2016 using a RCBD with four replications on the cabbage variety Gazelle. For the trial sufficient natural infestation of S. exigua and T. ni was present. Plants were transplanted on September 20th and the first insecticide application was performed 2 weeks later on October 4th. Treatments included an untreated control, spinetoram, Spexit $(180 \mathrm{ml} / \mathrm{ha})+$ spinetoram + Loopex $(200 \mathrm{ml} / \mathrm{ha})$, Spexit $(180 \mathrm{ml} / \mathrm{ha})+$ spinosad + Loopex $(200 \mathrm{ml} / \mathrm{ha})$, as well as Methoxyfenozide. On each plot $(4 \times 15 \mathrm{~m})$ the application number and interval for each treatment was chosen according to product standards. Efficacy was evaluated by using a damage assessment of the final yield of marketable heads [\%] from 25 plants. Data were analyzed using analysis of variance, followed by the LSD post-hoc test.

\section{Helicovex (HearNPV) on Sweet Corn}

The efficacy of Helicovex in combination with chlorantraniliprole, spinetoram, and the pyrethroid insecticides zeta-cypermethrin and lambda-cyhalothrin to control $H$. zea in sweet corn was assessed in Lafayette, Indiana (USA) using a RCBD with four replications. The trial was conducted by the Department of Entomology of Purdue University on a field of Meigs Horticultural Facility on the sweet corn variety Obsession. For the trial sufficient natural infestation of $H$. zea was present.
The stage of the crop in the field was at approximately $43 \%$ silk when the first application was made on 22nd August. Sprays to protect the ears were applied as recommended for each product. Helicovex was applied in tank mix or rotation with standard chemical products in the respective strategy at a high $(90 \mathrm{ml} / \mathrm{ha})$ and a low rate $(40 \mathrm{ml} / \mathrm{ha})$. The $40 \mathrm{ml} / \mathrm{ha}$ rate of Helicovex equals $3.00 \times 10^{11} \mathrm{OB} / \mathrm{ha}$ and the $90 \mathrm{ml} /$ ha equals $6.75 \times 10^{11} \mathrm{OB} / \mathrm{ha}$. The assessment was performed on 11th September by 25 ears of marketable size harvested from the middle two rows of each plot and evaluated for the amount of tip damage, number of damaged kernels and the number of live caterpillars. Ears with no visible insect feeding damage were rated as clean. Data were analyzed using analysis of variance, followed by the Tukey post-hoc test.

\section{RESULTS}

\section{Spexit (SeNPV) on Tomato}

The high application rate of Spexit in standalone was highly effective in controlling S. exigua infestations on tomato. The percentage of damaged fruit was reduced from over 35\% in the untreated control to $10 \%$, resulting in an efficacy of $72 \%$ (Figure 1). The low application rate of Spexit showed a lower but still significant $(p<0.05)$ reduction of the percentage of damaged fruit, from 35 to $23 \%$ with an efficacy of $39 \%$. Furthermore, the low dosage of Spexit increased the efficacy of the Bta in a tankmix, however the difference was not significant. Thus, Spexit provides good control of the beet armyworm when used stand-alone or in combination with Bt.

\section{Loopex (AcNPV) on Broccoli}

All treatments significantly $(p<0.05)$ reduced the number of T. ni larvae on broccoli (Figure 2). The tested baculovirus combinations reached the same level of control as the standard control strategies for T. ni. The application of the higher rate of Loopex resulted in a consistent low number of larvae during the first half of the trial period and was at the same level as the Btk modality toward the end of the trial. The high rate of Loopex reached an average efficacy of $75 \%$ compared to $65 \%$ of Btk. The lower rate in combination with Btk could be favorable when secondary pests are available.

\section{Spexit (SeNPV) and Loopex (AcNPV) on Cabbage}

Spexit and Loopex showed good efficacy in an application strategy with conventional insecticides on cabbage against $S$. exigua and $T$. ni. All treatments shown significantly $(p<$ 0.05 ) increased marketable heads. The percentage of marketable cabbage heads did not differ significantly when treated with Spexit and Loopex as compared to the treatment with spinetoram (Figure 3).

\section{Helicovex (HearNPV) on Sweet Corn}

The pyrethroid insecticides, lambda-cyhalothrin and zetacypermethrin, performed poorly when applied alone and in combination with chlorantraniliprole against $H$. zea on sweet corn (Table 1). The best control in the trial was achieved by two strategies including combinations of active 


\section{Damaged fruit [\%]}

\section{Untreated Control}

Spexit $(75 \mathrm{ml} / \mathrm{ha})$

Bta $(1.1 \mathrm{~kg} / \mathrm{ha})$ Spinosad (300 ml/ha)

Bta $(1.1 \mathrm{~kg} / \mathrm{ha})$

Spexit $(180 \mathrm{ml} / \mathrm{ha})$

Spinosad $(300 \mathrm{ml} / \mathrm{ha})$

Bta $(1.1 \mathrm{~kg} / \mathrm{ha})$

Spexit $(75 \mathrm{ml} / \mathrm{ha})$

Spexit $(180 \mathrm{ml} / \mathrm{ha})$

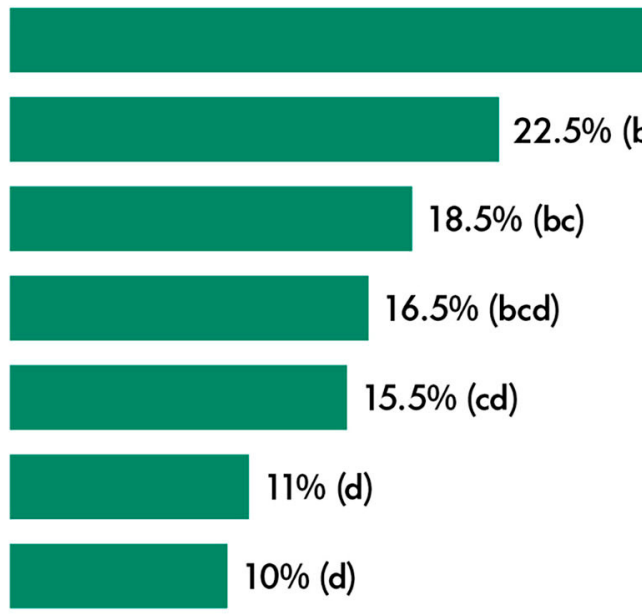

$10 \%(d)$
Efficacy

$37 \%$ (a)

$38.8 \%$

$50 \%$

$54.7 \%$

$56.9 \%$

$68.6 \%$

$72.2 \%$

Trial conducted by Two Bees Agricultural Research and Consulting, Escalon, CA, 2016

FIGURE 1 | Efficacy (\%) based on the mean percentage of damaged tomato fruits of the different treatments. Spexit was used in two different application rates, tankmixed with Bta as well as in rotation with spinosad. Data were analyzed using analysis of variance, followed by the LSD post-hoc test. Significance was determined by $p<0.05$ and is shown by letters $(a-d)$.

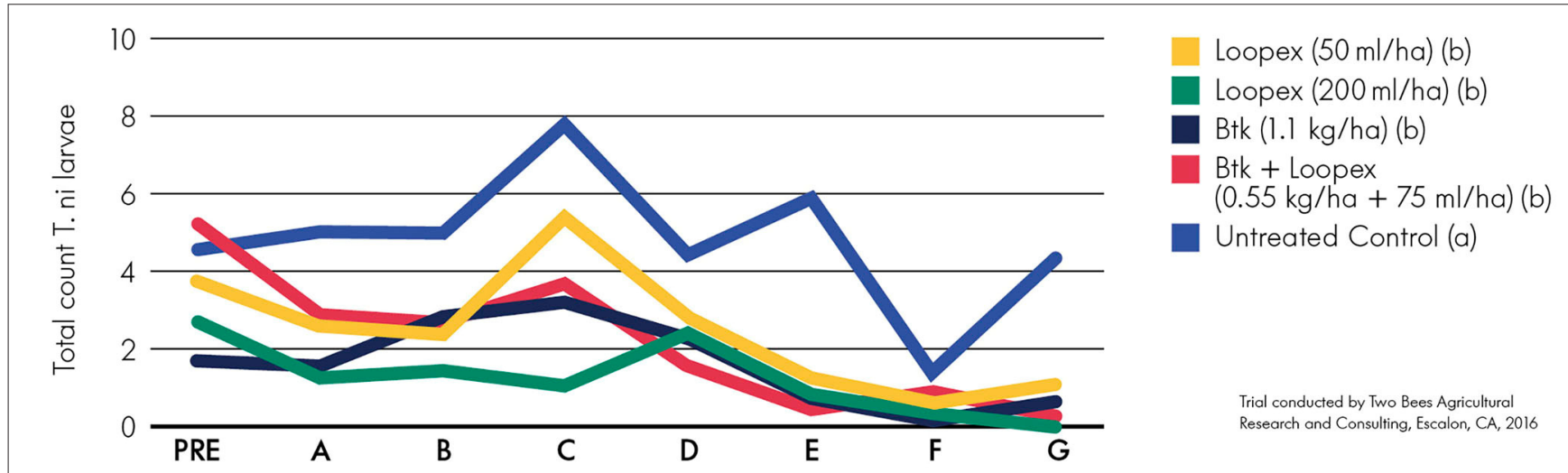

FIGURE 2 | Total mean number of T. ni larvae at the different assessment dates for the treatments (A-G are assessments 1 day after each treatment). Loopex was applied in two different application rates on broccoli alone or tankmixed with Btk. Data were analyzed using analysis of variance, followed by the LSD post-hoc test. Significance was determined by $p<0.05$ and is shown by letters $(a, b)$.

ingredients. Three applications of chlorantraniliprole with two applications of Helicovex increased the percentage of clean ears from $3 \%$ in the untreated control to 57\%. Applying chlorantraniliprole with spinetoram in comparison yielded clean ears in $47 \%$. When applying a combination of lambdacyhalothrin, chlorantraniliprole and spinetoram 56\% of clean ears were found in the plots.

\section{DISCUSSION AND CONCLUSIONS}

The field trials showed that baculovirus products provide a control of target pests comparable to USDA tolerance standards (United States Department of Agriculture, 2020) when applied as stand-alone or in rotations and tankmixes with chlorantraniliprole, Bacillus thuringinesis products and spinosad.

Baculovirus insecticides like Spexit, Loopex, and Helicovex can be successfully included in application strategies together with conventional insecticides which have a broader spectrum of activity. This opens many possibilities to meet the criteria for environmentally friendly and residue reduced production by reducing inputs of other insecticides. At the same time control of pest complexes is ensured. The successful implementation of such a strategy generally requires adequate information on the biology of prevailing seasonal pest, since baculovirus insecticides 


\section{Marketable heads [\%]}

Chlorfenapyr $(730 \mathrm{ml} / \mathrm{ha})(\mathrm{ABCD})$

$97.8 \%(a)$

Spinetoram $(370 \mathrm{ml} / \mathrm{ha})(A B C)$

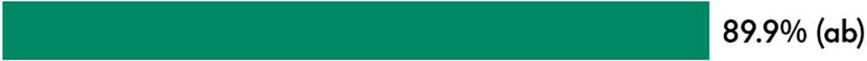

Spexit $(180 \mathrm{ml} / \mathrm{ha})(A)$ Spinosad (430 ml/ha) (B) Loopex (200 ml/ha) (CD)

Spexit $(180 \mathrm{ml} / \mathrm{ha})$ (A) Spinetoram $(430 \mathrm{ml} / \mathrm{ha})(B)$ Loopex (200 ml/ha) (CD)

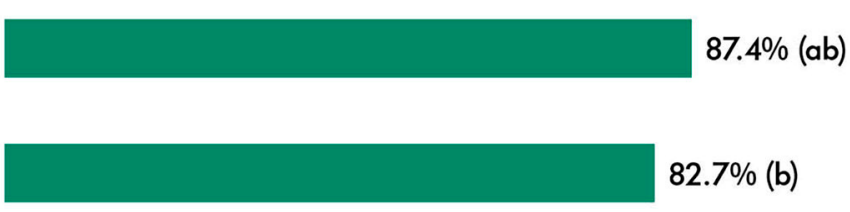

Untreated Control

$42.9 \%(d)$

Trial conducted by Two Bees Agricultural Research and Consulting, Escalon, CA, 2016

FIGURE 3 | Mean percentage of marketable cabbage heads depending on the treatment. A, B, C, and D represent application dates with intervals of 7-12 days. Data were analyzed using analysis of variance, followed by the LSD post-hoc test. Significance was determined by $p<0.05$ and is shown by letters (a,b,d).

TABLE 1 | Mean percentage clean ears.

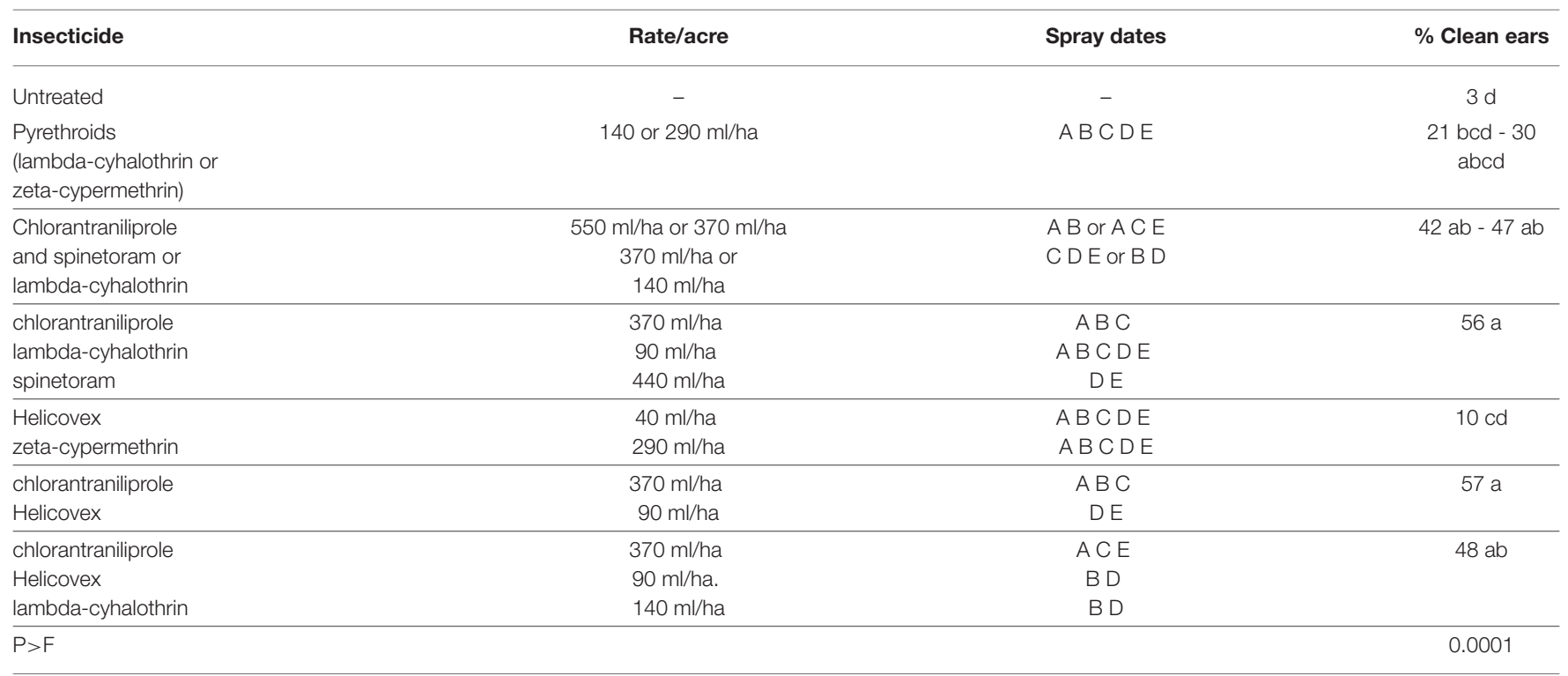

Treatments were applied on 24 (A), 28 (B), 31 (C) August, and 4 (D) and 7 (E) September. Means followed by the same letter are not significantly different (Tukey HSD). Best results were achieved by the combinations of chlorantraniliprole with Helicovex (57\% clean ears) and chlorantraniliprole with lambda-cyhalothrin and spinetoram (56\% clean ears). Data were analyzed using analysis of variance, followed by the Tukey post-hoc test. Significance was determined by $p<0.05$.

target larval stages of Lepidopterans and act only by ingestion. Therefore, efficacy can be improved by reliable monitoring of the pest species.

The conducted trial for control of $S$. exigua populations on tomato compared standard applications of Bta and spinosad to the combination with the baculovirus product Spexit. Adding a low dosage of Spexit to the Bta treatment in this trial indicated a reduction of the number of damaged fruit when compared to the Bta treatment alone. Thus, this trial demonstrates a potential additional efficacy on fruit damage as compared to the standard application strategies.
Such a direct benefit of adding baculoviruses was not seen in the trials on cabbage, broccoli and sweet corn. The trials for control of T. ni larvae on broccoli and S. exigua and T. ni on cabbage demonstrate that the baculovirus treatments reach the same control level as the accepted control strategy. There may be various reasons that lead to no additional control by adding baculoviruses in a field trial. Such reasons include overall plant health, weather developments during the trial such as temperature and rain leading to changes in population dynamics of the pest. For example the cabbage trial had a relatively low larval infestation and therefore, further differences between 
treatments may not have been detected. Furthermore, efficacy on damage control of baculoviruses is generally best when applied to newly hatched larvae as compared to late larval instars. The timing of the first application therefore is an essential point of a field trial. Of the presented trials, the first application was only determined by trap catches in the tomato trial. Therefore, the different determination of the timing of the first application may provide a further explanation to differing efficacy in these trials.

Besides a direct effect of adding baculoviruses seen by improved efficacy as in the tomato trial, there are benefits for resistance management in integrated plant protection. The use of multiple insecticidal modes of actions is assumed to reduce the rates at which resistance may build up (Helps et al., 2020). As baculoviruses have a different mode of action from chemical insecticides, their adoption is likely to strengthen a resistance management strategy.

The sweet corn trial demonstrated poor efficacy of pyrethroids products, which could be related to pest resistance as there are reports of reduced susceptibility of different lepidopteran species such as H. zea to pyrethroids (Rabelo et al., 2020). This is especially important in fresh market crops such as sweet corn, as the tolerance for damage is very low. Only one larva already makes the produce unmarketable for the fresh market (Olmstead and Shelton, 2016). Additionally, the window for treatments with foliar insecticides for pest management is very narrow because the larvae of $H$. zea only spend a very short time outside the ear before entering into the silks and becoming protected within the ears (Reay Jones, 2019). Methomyl, chlorantraniliprole and lambda-cyhalothrin are commonly used in IPM practices for control of H. zea in the USA (Olmstead and Shelton, 2016). Levels of control of chlorantraniliprole and spinetoram were not satisfying in this trial as resistance to these active ingredients has been confirmed on other pests (Zhu et al., 2017; Wang et al., 2018; Silva et al., 2019), beginnings of early resistance selection might be an explanation to the low control in this trial. In this case, including baculoviruses into the spray program could be a good option to delay resistance selection. A field trial conducted by Olmstead and Shelton (2016) compared efficacy of chlorantraniliprole and pyrethroids when the application timing

\section{REFERENCES}

Ditillo, J., Kenedy, G., and Walgenbach, J. (2016). Effects of insecticides and fungicides commonly used in tomato production on Phytoseiulus persimilis (Acari: Phtyoseiidae). J. Econ. Entomol. 109, 2298-2308. doi: $10.1093 /$ jee/tow234

Environmental directorate, Organisation for Economic Co-operation and Development (2002). Consensus document on information used in the assessment of environmental applications involving baculoviruses. Series on harmonization of regulatory oversight in biotechnology.

Environmental Protection Agency (2014). Tolerances and exemptions for pesticide chemical residues in food. Protect. Environ. 40:180.

Farrar, R., Shepard, B., Shapiro, M., Hassell, R., Schaffer, M., and Smith, C. (2009). Supplemental control of lepidopterous pests on Bt transgenic sweet corn with biologically-based spray treatments. J. Insect Sci. 9:8. doi: 10.1673/031.00 9.0801

Fernandes, M., Alves, F., Pereira, R., Aquino, L., Fernandes, F., and Zanuncio, J. (2016). Lethal and sublethal effects of seven insecticides on three beneficial was based on common IPM decision guidelines and based on plant phenology. The trial produced some inconsistent results regarding the effect of timing on control of damage by $H$. zea. However, the direct comparison of the active ingredients when following the IPM decision guidelines gave a clear result. The percentage of undamaged ears in the IPM treatment of Chloantraniliprole, lambda-cyhalothrin and Methomyl was $75.8,65.5$, and 45.5\%, respectively. A direct comparison of efficacy levels with the present study is difficult because of the considerable variation of the pest pressure between the trials. However, in both trials, adding a baculovirus for pest control resulted in higher efficacy in all treatments, indicating an advantage of such strategies in practice.

Another example of adding baculoviruses into a control strategy has previously been discussed by Farrar et al. (2009). In field trials with transgenic Bt corn, including baculoviruses such as SfMNPV and HzSNPV to control Spodoptera frugiperda and $H$. zea could reduce the relative damage as well as the number of larvae per ear. The authors concluded that therefore, biological spray insecticides could be useful tools to improve control of $H$. zea and S. frugiperda.

The conducted trials in open field and protected vegetables show that baculoviruses can offer an effective solution to control pests in open field and protected vegetable production. Including baculoviruses gave results as good as other application strategies tested while conferring important benefits in reducing residues and improving the resistance management strategy.

\section{DATA AVAILABILITY STATEMENT}

The data analyzed in this study is subject to the following licenses/restrictions: Dataset is property of Andermatt Biocontrol Suisse AG. Requests to access these datasets should be directed to Anna Landwehr, anna.landwehr@biocontrol.ch.

\section{AUTHOR CONTRIBUTIONS}

The author confirms being the sole contributor of this work and has approved it for publication. insects in laboratory assays and field trials. Chemosphere 156, 45-55. doi: 10.1016/j.chemosphere.2016.04.115

Galvan, T., Koch, R., and Hutchinson, W. (2005). Toxicity of commonly used insecticides in sweet corn and soybean to multicolored asian lady beetle (Coleoptera: Coccinellidae). J. Econ. Entomol. 98, 780-780. doi: 10.1603/0022-0493-98.3.780

Harrison, R., and Hoover, K. (2012). "Baculoviruses and other occluded insect viruses” in Insect Pathology, ed K. Hoover (Beltsville, MD: Elsevier), 73-131. doi: 10.1016/B978-0-12-384984-7.00004-X

Helps, J. C., Paveley, N. D., White, S., and van den Bosch, F. (2020). Determinants of optimal insecticide resistance management strategies. J. Theoret. Biol. 503:110383. doi: 10.1016/j.jtbi.2020.110383

Lacey, L., Thomson, D., Vincent, C., and Arthurs, S. (2008). Codling moth granulovirus: a comprehensive review. Biocont. Sci. Technol. 18, 639-663. doi: 10.1080/09583150802267046

Lacey,. L., Grzywacz, D., Shapiro-Ilan, D. J., Frutos, R., Brownbridge, M., and Goettel, M. S. (2015). Insect pathogens as biological control agents: back to the future. J. Inverteb. Pathol. 132, 1-41. doi: 10.1016/j.jip.2015.07.009 
Lasa, R., Pagola, I., Ibanez, I., Belda, J., Williams, T., and Caballero, P. (2007). Efficacy of Spodoptera exigua nucleopolyhedrovirus as a biological insecticide for beet armyworm control in greenhouses of southern Spain. Biocont. Sci. Technol. 17, 221-232. doi: 10.1080/09583150701 211335

Moscardi, F., de Souza, M. L., de Castro, M. E. B., Moscardi, M. L., and Szewczyk, B. (2011). "Baculovirus pesticides: present state and future perspectives," in: Microbes and Microbial Technology, ed I. Ahmad, F. Ahmad, and J. Pichtel (New York, NY: Springer), 415-445. doi: 10.1007/978-1-4419-7931-5_16

Olmstead, D., and Shelton, A. (2016). Effects of timing and insecticide on management of Helicoverpa zea (Lepidoptera: Noctuidae) in sweet corn (Poales: Poaceae). Florida Entomol. 99, 161-163. doi: 10.1653/024. 099.0201

Rabelo, M., Paula-Moraes, S., Pereira, E., Siegfried, B. (2020). Contrasting susceptibility of lepidopteran pests to diamide pyrethroid insecticides in a region of overwintering and migratory intersection. Pest Manage. Sci. 76, 4240-4247. doi: 10.1002/ps.5984

Reay Jones, F. (2019). Pest status and management of corn earworm (Lepidoptera: Noctuidae) in field corn in the united states. J. Integrat. Pest Manage. 10, 1-9. doi: $10.1093 / \mathrm{jipm} / \mathrm{pmz} 017$

Silva, J., Ribeiro, L., Vinasco, N., Guedes, R., and Siqueira, H. (2019). Fieldevolved resistance to chlorantraniliprole in the tomato pinworm Tuta absoluta: inheritance, cross-resistance profile and metabolism. J. Pest Sci. 92, 1421-1431. doi: 10.1007/s10340-018-1064-Z

Smagghe, G., Deknopper, J., Meeus, J., and Mommaerts, V. (2013). Dietary chlorantraniliprole suppresses reproduction in worker bumblebees. Pest Manage. Sci. 69, 787-791. doi: 10.1002/ ps.3504

Szewczyk, B., Rabalski, L., Krol, E., Sihler, W., and de Souza, M. L. (2009). Baculovirus biopesticides - a safe alternative to chemical protection of plants. J. Biopestici. 2, 209-216.

United States Department of Agriculture. (2020). Vegetables. Available online at: https://www.ams.usda.gov/grades-standards/vegetables (accessed December 15, 2020).

Wang, X., Chen, Y., Gong, C., Yao, X., Jiang, C., and Yang, Q. (2018). Molecular identification of four novel cytochrome P450 genes related to the development of resistance of Spodoptera exigua (Lepidoptera: Noctuidae) to chlorantraniliprole. Pest Manage. Sci. 74, 1938-1952. doi: 10.1002/ps.4898

Zhu, B., Li, X., Liu, Y., Gao, X., and Liang, P. (2017). Global identification of microRNAs associated with chlorantraniliprole resistance in diamondback moth Plutella xylostella (L.). Sci. Rep. 7:40713. doi: 10.1038/srep40713

Conflict of Interest: AL was employed by company Andermatt Biocontrol Suisse AG.

Copyright (c) 2021 Landwehr. This is an open-access article distributed under the terms of the Creative Commons Attribution License (CC BY). The use, distribution or reproduction in other forums is permitted, provided the original author(s) and the copyright owner(s) are credited and that the original publication in this journal is cited, in accordance with accepted academic practice. No use, distribution or reproduction is permitted which does not comply with these terms. 